\title{
Mixed anxiety-depression in a 1 year follow-up study: shift to other diagnoses or remission?
}

\author{
Katrin Barkow ${ }^{\text {a }}$, Reinhard Heun ${ }^{\text {a }}$, Hans-Ulrich Wittchen ${ }^{\text {b }}$, T. Bedirhan Üstün ${ }^{\text {c }}$, Michael \\ Gänsicke ${ }^{\mathrm{a}}$, Wolfgang Maier ${ }^{\mathrm{a}}$ \\ a Department of Psychiatry, University of Bonn, Germany \\ b Max Planck Institute of Psychiatry, Munich, Germany \\ c World Health Organization, Geneva, Switzerland
}

\begin{abstract}
Background: In 1992, the ICD-10 introduced the concept of mixed anxiety-depression disorder (MAD). However, a study examining the stability of this ICD-10-diagnosis is lacking. Our objective was to examine the 12 month outcome of MAD in comparison to the outcome of depression, anxiety, and comorbid depression and anxiety. Methods: 85 MAD patients, 496 patients with major depression, 296 patients with anxiety disorders, and 306 comorbid patients were reassessed after 12 months. Rates of depression, anxiety, and MAD were compared using $\chi 2$-tests. Results: While depressive disorders and anxiety disorders showed relatively high stability, MAD Patients had no higher rates of MAD at follow-up than patients with depression, anxiety or both. Limitations: Detailed information regarding treatment and disorders during the follow-up interval was lacking. Prevalence rates of MAD in single centres were too small for contrasting centres. Conclusions: MAD cannot be seen as a stable diagnosis: Most of MAD patients remit; many of them shift to other diagnoses than depression or anxiety. The ICD-10 criteria have to be specified more exactly.
\end{abstract}

Keywords: Mixed anxiety-depression; Stability; Validity; Epidemiology

\section{Introduction}

A substantial number of patients suffer from depressive and anxiety symptoms without meeting official criteria of either ICD-10 or DSM-IV depressive and/or anxiety disorders (Zinbarg et al., 1994; Stein et al., 1995; see Katon and Roy-Byrne, 1991; Wittchen and Essau, 1993; Boulenger et al., 1997 for reviews). These patients are frequent in primary care (Barrett et al., 1988; Wittchen and Essau, 1993; Barlow and Campbell, 2000). To provide a clinical definition for those patients the ICD-10 (WHO, 1992) introduced the concept of mixed anxiety-depression disorder (MAD). The criteria for MAD are as follows:

1. Presence of mild or moderate anxiety and depression, without prevailing of anxiety or depression,

2. at least temporary occurrence of vegetative symptoms,

3. the symptoms do not fulfil the criteria of an anxiety disorder or a depressive episode.

The status of the ICD-10-MAD diagnosis - in relation to depressive and anxiety disorders needs further research. There is a need for follow-up studies - explicitly applying the specified diagnostic criteria of the ICD-10 - to determine the temporal stability of a given ICD-10-MAD diagnosis and the possible shift to depressive and/or anxiety disorders (see also Katon and Roy-Byrne, 1991; Wittchen and Essau, 1993; Stein et al., 1995). This study examines the outcome of a given ICD-10-MAD diagnosis as compared to depression and anxiety after one year in a primary care sample in terms of the diagnostic status. Data were collected within the scope of the World Health Organization (WHO) Collaborative Study on 
'Psychological Problems in General Health Care', which is a cross-sectional and prospectivelongitudinal international study (Sartorius et al., 1993; Üstün and Sartorius, 1995).

\section{Methods}

From the sample of the WHO Collaborative Study1 patients meeting ICD-10 criteria for a depressive episode, dysthymia, agoraphobia, panic disorder, generalised anxiety disorder (GAD), comorbid depressive and anxiety disorder, and MAD at the baseline assessment were identified and reassessed after 12 months. Additional ICD-10 psychiatric diagnoses were allowed. Patients older than 65 years were excluded. ICD-10 diagnoses were obtained using the Composite International Diagnostic Interview- Primary Health Care Version (CIDI-PHC), a modification of the Composite International Diagnostic Interview (CIDI; Division of Mental Health, 1990). The interviewer-observer reliability coefficient (across different centres) of the CIDI-PHC was 0.92 overall, ranging between 0.81 to 1.0 on the item level. For this coefficient a total of 19 videotaped interviews were circulated between the centres.

For the statistical analysis, single diagnoses were combined to depressive disorders, anxiety disorders, comorbid depressive and anxiety disorder, and MAD. Frequency analyses were conducted using SPSS (SPSS Inc, Chicago, Ill). Single comparisons within the whole contingency table were carried out (Jesdinsky, 1968). Presence of the diagnosis under examination was tested against absence (i.e. combined possible outcome categories). The significance level was always set at 1 - sided $\mathrm{P}<0.05$. It was corrected for multiple testing applying the Bonferoni-procedure if necessary.

\section{Results}

\subsection{Sample characteristics}

A total of 1856 patients were identified to meet ICD- 10 criteria for a depressive episode, dysthymia, agoraphobia, panic disorder, GAD, comorbid anxiety and depressive disorder, and MAD at the baseline diagnostic assessment. 1183 subjects $(63.7 \%)$ could be re-examined at the follow-up. A total of $673(36.3 \%)$ did not participate in the follow-up examination because they had moved and were not found anymore, because of refusal or because of death. Exact proportions were not recorded. There was no significant difference between participants and non-participants regarding sex (participants: proportion female $=73.1 \%$, non-participants: proportion female $=72.5 \% ; \chi 2=0.80, \mathrm{df}=1, \mathrm{P}=0.777$ ), and statistically significant but slight differences regarding age (participants' mean age $=39.67$, non-participants' mean age $=40.95$; $\mathrm{t}=-2.025, \mathrm{df}=1854, \mathrm{P}=0.043)$. The study sample of the baseline assessment is described in Table 1.

\subsection{Twelve month outcome}

MAD, depressive episodes, dysthymia, agoraphobia, panic disorder only, GAD, and comorbid depressive and anxiety disorder showed a substantial improvement (average remission rate: $41.9 \%$ ). $16.7 \%$ of all patients had exactly the same ICD-10-diagnosis at both assessments with MAD showing the lowest rate of stable diagnoses (1.2\%). The majority of MAD patients remitted or shifted to other (non-depressive and non-anxiety) diagnoses (see Table 2).

Table 2 shows the 12 month outcome of combined diagnoses. As was expected, follow-up rates of depressive disorders were higher in patients with depression and comorbid patients at baseline as compared to patients with an anxiety disorder at baseline $(\chi 2=8.84, \mathrm{df}=1, \mathrm{P}<$ 
$0.01 ; \chi 2=6.00, \mathrm{df}=1, \mathrm{P}<0.05$, respectively). Follow-up rates of anxiety disorders were higher in patients with an anxiety disorder and comorbid patients at baseline as compared to patients with a depressive disorder at baseline $(\chi 2=21.71, \mathrm{df}=1, \mathrm{P}<0.001 ; \chi 2=13.25, \mathrm{df}=1, \mathrm{P}$ $<0.001$, respectively). There were no differences regarding follow-up depression rates between patients with a depressive disorder and comorbid patients $[\chi 2=0.01, \mathrm{df}=1$, not significant (n.s.)] and no significant differences regarding follow-up anxiety rates between patients with an anxiety disorder and comorbid patients at baseline $\left(\chi^{2}=0.9065\right.$, $\mathrm{df}=1$, n.s.).

There were no differences regarding follow-up MAD rates between patients with MAD and those with a depressive disorder $\left(\chi^{2}=0.92, \mathrm{df}=1, \mathrm{n}\right.$.s. $)$, those with an anxiety disorder $\left(\chi^{2}=\right.$ $0.09, \mathrm{df}=1, \mathrm{n} . \mathrm{s}$.$) , and those with comorbid depression-anxiety at baseline (\chi 2=0.38, \mathrm{df}=1$, n.s.).

Follow-up rates of depressive disorders were not significantly lower in patients with MAD as compared to patients with a depressive disorder at baseline $(\chi 2=2.00, \mathrm{df}=1, \mathrm{n} . \mathrm{s}$. $)$ and to those with comorbid depression-anxiety at baseline $(\chi 2=1.45, \mathrm{df}=1$, n.s. $)$ although there was a trend in the expected direction.

Follow-up rates of anxiety disorders were not significantly lower in patients with MAD as compared to those with an anxiety disorder at baseline $(\chi 2=5.07, \mathrm{df}=1$, n.s. $)$ and to those with comorbid depression- anxiety at baseline $\left(\chi^{2}=2.65, \mathrm{df}=1, \mathrm{n} . \mathrm{s}\right.$. $)$, although a trend in this direction is obvious.

\section{Discussion}

The data presented herein did not show temporal stability of MAD as compared to depressive and anxiety disorders. Our results are in contrast to the findings of Usall and Marquez (1999) who concluded that MAD is a stable diagnosis. These authors applied DSM-IV research criteria so that their results cannot be directly compared with our findings.

\subsection{Implications}

ICD-10 MAD criteria are relatively vague compared to DSM-IV research criteria (APA, 1994) clearly specifying symptoms necessary for the MAD diagnosis. Although ICD-10 and DSM-IV are similar regarding organisation, designations of disorders, abandonment of theoretical disease concepts, and criteria based diagnostics there are important differences regarding single diagnoses, partly due to the fact that the DSM-IV was developed for the USA while the ICD-10 serves as a guideline for diagnostics worldwide leading to more compromises in the ICD-10.

A revision of the ICD-10 MAD diagnosis seems necessary. For such a revision several possibilities are conceivable: Preskorn and Fast (1993) argue against a MAD diagnosis and are in favour of a careful psychiatric assessment resulting in either depression or anxiety diagnoses. Others proposed a non-specific negative affect as common diathesis for anxiety and depression (Clark and Watson, 1991; Barlow and Campbell, 2000), which would have extensive consequences for the diagnostic manuals. The results presented herein do not allow for statements about the relationship between anxiety, depression and MAD. Therefore, future research is necessary.

Either way, the present study shows that an assiduous psychiatric assessment incorporating longitudinal information (i.e., medical history and follow-up assessments) is indispensable. Of 
course, the question arises whether the ICD-10 classification lives up to rather minor disorders frequently seen in primary care and whether an appropriate ICD-10 diagnosis suffices. [Also other diagnoses assessed herein changed diagnostic category relatively frequently (Table 2)]. Especially in minor disorders, where psychotherapeutical approaches play an important role, the formulation of an individual disease model and an according treatment is much more determining.

\subsection{Limitations}

Depressive and anxiety disorders might be more severe disorders than MAD, therefore, more easily remitting. Nevertheless, the remission rates for the other disorders were also quite high. Moreover, GAD which also can be seen as relatively mild psychiatric condition shows a high degree of chronicity (Mancuso et al., 1993; Schweizer, 1995; Woodman et al., 1999).

Prevalence rates of MAD in single centres were to small for contrasting outcomes of this diagnosis between different centres so that probable socio-cultural differences are not shown.

One might speculate that the exclusion of elderly patients resulted in an overestimation of instability of MAD: The more unknown and shorter medical history in younger patients probably leads to more diagnoses of MAD that might in turn be revised after a certain time span. In older patients with longer illness histories a MAD diagnosis might not be so easily corrected. On the other hand, the frequency of MAD might decline in the elderly for the same reasons.

Other limitations are lacking information regarding treatment and remissions and relapses during the follow-up.

Socio-demographic characteristics of patients separated for different poychiatric disorders at baseline

\begin{tabular}{|c|c|c|c|c|c|}
\hline & $\begin{array}{l}\text { Depressive } \\
\text { disorder } \\
n(\%)\end{array}$ & $\begin{array}{l}\text { Anxiety } \\
\text { disorder } \\
n(\%)\end{array}$ & $\begin{array}{l}\text { Comorbid } \\
\text { depressive and } \\
\text { anxiety disorder } \\
n(\%)\end{array}$ & $\begin{array}{l}\text { MAD } \\
n(\%)\end{array}$ & $\begin{array}{l}\text { Total } \\
n(\%)\end{array}$ \\
\hline Proportion female & $360(72.6)$ & $211(71.3)$ & $225(26.0)$ & $69(81.2)$ & $865(73.1)$ \\
\hline Age [Mean (SD)] & 38.58 (1294) & $44.04(12.54)$ & $42.28(12.26)$ & $39.16(12.96)$ & $40.95(12.87)$ \\
\hline \multicolumn{6}{|l|}{ Centre } \\
\hline Ankara & $85(17.1)$ & $7(2.4)$ & $6(2.0)$ & $7(8.2)$ & $105(8.9)$ \\
\hline Athens & $10(2.0)$ & $20(6.8)$ & $17(5.6)$ & $3(3.5)$ & $50(4.2)$ \\
\hline Bangalore & $47(9.5)$ & $16(5.4)$ & $31(10.1)$ & $3(3.5)$ & $97(8.2)$ \\
\hline Berlin & $28(5.6)$ & $46(15.5)$ & $15(4.9)$ & $9(10.6)$ & $98(8.3)$ \\
\hline Groningen & 59 (11.9) & $21(7.1)$ & $40(13.1)$ & $6(7.1)$ & $126(10.7)$ \\
\hline lbadan & $9(1.8)$ & $8(2.7)$ & $7(2.3)$ & $8(9.4)$ & $32(2.7)$ \\
\hline Mainz & $19(3.8)$ & $27(9.1)$ & $17(5.6)$ & $6(7.1)$ & $69(5.8)$ \\
\hline Manchester & $51(10.3)$ & $27(9.1)$ & $52(17.0)$ & $5(5.9)$ & $135(11.4)$ \\
\hline Nagasaki & $8(1.6)$ & $14(4.7)$ & $4(1.3)$ & $1(1.2)$ & $27(2.3)$ \\
\hline Paris & $47(9.5)$ & $25(8.4)$ & $35(11.4)$ & $7(8.2)$ & $114(9.6)$ \\
\hline Rio de Janeiro & $15(3.0)$ & $25(8.4)$ & $21(6.9)$ & $4(4.7)$ & $65(5.5)$ \\
\hline Santiago de Chile & $30(6.0)$ & $22(7.4)$ & $25(8.2)$ & $8(9.4)$ & $85(7.2)$ \\
\hline Seattle & $38(7.7)$ & $15(5.1)$ & $11(3.6)$ & $4(4.7)$ & $68(5.7)$ \\
\hline Shanghai & $29(5.8)$ & $11(3.7)$ & $12(3.9)$ & $8(9.4)$ & $60(5.1)$ \\
\hline Verona & $21(4.2)$ & $12(4.1)$ & $13(4.2)$ & $6(7.1)$ & $52(4.4)$ \\
\hline Total & $496(100)$ & $296(100)$ & $306(100)$ & $85(100)$ & $1183(100)$ \\
\hline
\end{tabular}




\begin{tabular}{|c|c|c|c|c|c|c|c|}
\hline \multirow[b]{2}{*}{$\begin{array}{l}\text { Combined base line } \\
\text { ICD-10 diagnosis }\end{array}$} & \multicolumn{7}{|c|}{ Combined ICD-10 diagnoses at 12 month follow-up } \\
\hline & $\begin{array}{l}\text { Fully recovered/ } \\
\text { no ICD-10 } \\
\text { disorder } \\
n(\%)\end{array}$ & $\begin{array}{l}\text { Depressive } \\
\text { disorder } \\
n(\%)\end{array}$ & $\begin{array}{l}\text { Anxiety } \\
\text { disorder }^{b} \\
n(\%)\end{array}$ & $\begin{array}{l}\text { Comorbid } \\
\text { depressive and } \\
\text { anxiety disorder } \\
n(\%)\end{array}$ & $\begin{array}{l}\text { MAD } \\
n(\%)\end{array}$ & $\begin{array}{l}\text { Solely other } \\
\text { ICD-10 } \\
\text { disorder } \\
n(\%)\end{array}$ & $\begin{array}{l}\text { Total number } \\
\text { of patients } \\
n(\%)\end{array}$ \\
\hline MAD & $42(49.4)$ & $9(10.6)$ & $8(9.4)$ & $6(7.1)$ & $1(1.2)$ & $19(22.4)$ & $85(100)$ \\
\hline Depressive disorder ${ }^{n}$ & $235(47.4)$ & $81(16.3)$ & $36(7.3)$ & $67(13.5)$ & $14(2.8)$ & $63(12.7)$ & $496(100)$ \\
\hline Anxiety disorder ${ }^{b}$ & $133(44.9)$ & $26(8.8)$ & $55(18.6)$ & $31(10.5)$ & $4(1.4)$ & $47(15.9)$ & $296(100)$ \\
\hline $\begin{array}{l}\text { Comorbid depressive } \\
\text { and arxiety disorder }\end{array}$ & $86(28.1)$ & $48(15.7)$ & $49(16.0)$ & $80(26.1)$ & $7(2.3)$ & $36(11.8)$ & $306(100)$ \\
\hline
\end{tabular}

${ }^{\mathrm{a}}$ Depressive episode or/and dysthymia.

${ }^{b}$ Agoraphobia or panic disorder or/and generalised anxiety disorder.

'Pain disorder, somatisation disorder, hypochondriasis, neurasthenia, alcohol harmful use/dependence.

\section{References}

- American Psychiatric Association (APA), 1994. Diagnostic and Statistical Manual of Mental Disorders, 4th Edition American Psychiatric Association, Washington, DC.

- Barlow, D.H., Campbell, L.A., 2000. Mixed anxiety - depression and its implications for models of mood and anxiety disorders. Compr. Psychiatry 41 (suppl. 1), 55- 60.

- Barrett, J.E., Barrett, J.A., Oxman, T.E., Gerber, P.D., 1988. The prevalence of psychiatric disorders in a primary care praxis. Arch. Gen. Psychiatry 45, 1100- 1106.

- Boulenger, J.-P., Fournier, M., Rosales, D., Lavallée, Y.-J., 1997. Mixed anxiety and depression: from theory to practice. J. Clin. Psychiatry 58 (suppl. 8), 27-34.

- Clark, L.A., Watson, D., 1991. Tripartite model of anxiety and depression: psychometric evidence and taxonomic implications. J. Abnorm. Psychol. 100, 316- 336.

- Division of Mental Health, 1990. CIDI-Core. Composite International Diagnostic Interview, Core Version 1.0-November 1990 WHO, Geneva.

- Jesdinsky, H.J., 1968. Einige $\chi 2$-Tests zur Hypothesenprüfung bei Kontingenztafeln [Some chi 2-tests for testing hypotheses in contingency tables]. Methods Inf. Med. 7, 187- 200.

- Katon, W., Roy-Byrne, P., 1991. Mixed anxiety and depression. J. Abnorm. Psychol. 100, 337- 345 .

- Mancuso, D.M., Townsend, M.H., Mercante, D.E., 1993. Longterm follow-up of generalized anxiety disorder. Compr. Psychiatry 34, 441- 446.

- Preskorn, S.H., Fast, G.A., 1993. Beyond signs and symptoms: The case against a mixed anxiety and depression category. J. Clin. Psychiatry 54 (suppl. 1), 24-32.

- Sartorius, N., Üstün, T.B., Costa e Silva, J.-A., et al., 1993. An international study of psychological problems in primary care. Preliminary report from the World Health Organization collaborative project on 'Psychological Problems in General Health Care'. Arch. Gen. Psychiatry 50, 819-824.

- Schweizer, E., 1995. Generalized anxiety disorder. Longitudinal course and pharmacologic treatment. Psychiatr. Clin. North Am. 18, 843- 857.

- Stein, M.B., Kirk, P., Prabhu, V., Grott, M., Terepa, M., 1995. Mixed anxiety-depression in a primary-care clinic. J. Affect. Disord. 34, 79- 84.

- Usall, J., Marquez, M., 1999. Trastorno mixto ansioso-depresivo: un estudio naturalistico [Mixed anxiety and depression disorder: a naturalistic study]. Actas Esp. Psiquiatr. 27, 81-86.

- Üstün, T.B., Sartorius, N. (Eds.), 1995. Mental Illness in General Health Care. An International Study Wiley, Chichester.

- Wittchen, H.-U., Essau, C.A., 1993. Comorbidity and mixed anxiety depressive disorders: Is there epidemiologic evidence? J. Clin. Psychiatry 54, $9-15$. 
- Woodman, C.L., Noyes, R., Black, D.W., Schlosser, S., Yagla, S.J., 1999. A 5 year follow-up study of generalized anxiety disorder and panic disorder. J. Nerv. Ment. Dis. 187, 3 -9.

- World Health Organization (WHO), 1992. The ICD-10 Classification of Mental and Behavioural Disorders. Clinical Descriptions and Diagnostic Guidelines WHO, Geneva.

- Zinbarg, R.E., Barlow, D.H., Liebowitz, M. et al., 1994. The DSMIV field trial for mixed anxiety depression. Am. J. Psychiatry 151, 1153- 1162. 